\title{
Mercados das agroindústrias familiares de queijo artesanal do Sudoeste do Paraná
}

\author{
Miguel Angelo Perondi \\ Universidade Tecnológica Federal do Paraná/Campus Pato Branco - Pato Branco \\ - Paraná - Brasil \\ Mariana Beal Dengo \\ Universidade Tecnológica Federal do Paraná/Campus Pato Branco - Pato Branco \\ - Paraná - Brasil \\ Marcio Gazolla \\ Universidade Tecnológica Federal do Paraná/Campus Pato Branco - Pato Branco \\ - Paraná - Brasil
}

\section{Resumo}

O objetivo do trabalho foi entender por que as agroindústrias familiares que produzem queijos artesanais formalmente legalizadas no Sistema de Inspeção Municipal (SIM) vendem nos mercados informais a maior parte da sua produção. Para atingir esse objetivo, metodologicamente, foram entrevistados seis produtores familiares de queijo, em quatro municípios da Região Sudoeste do Paraná, no ano de 2015. Os resultados e conclusões revelam um conjunto variado e multidimensional de elementos que atuam simultaneamente nas experiências e estruturam os mercados locais e informais. Os agricultores tentam 'driblar' os regramentos dos sistemas peritos alimentares e construir estratégias mais autônomas de desenvolvimento regional. Em resposta ao apelo dos consumidores por manter as características artesanais dos queijos vendidos nas cadeias curtas de comercialização. Por outro lado, também tentam se afastar do Estado, na medida em que, mesmo sendo formais perante o SIM, buscam a construção social dos seus mercados por fora das legislações e sistemas peritos alimentares que o ambiente institucional apregoa.

Palavras-chave: Mercados agroalimentares. Queijos artesanais. Informalidade. Sudoeste do Paraná. Desenvolvimento regional.

\section{Markets of artisanal cheese-based agroindustries in the Southwest of Paraná}

\section{Abstract}

The paper wants to understand why the artisanal cheeses family agroindustries that produce artisanal cheeses formally legalized in the Municipal Inspection System (SIM), they sell the majority part of production in the informal market. To achieve this goal, methodologically,

${ }^{1}$ Os autores agradecem ao Eng Agrônomo e Mestre Christophe De Lanoy pela sugestão de famílias e do problema de pesquisa, sem os quais, não teria sido possível delinear a pesquisa que resultou nesse artigo. 
six cheese family producers were interviewed in four municipalities in the Southwest Region of Paraná, in the year 2015. The results and conclusions reveal a varied and multidimensional set of elements that simultaneously act on the experiences and structure the local and informal markets. Farmers try to 'circumvent' the rules of food expert systems and build more autonomous regional development strategies. In response to the appeal of consumers to maintain the artisanal characteristics of cheeses sold in the short marketing chains. On the other hand, they also try to move away from the State, inasmuch as, even if they are formal by under State inspectional system, they seek the social construction of their markets outside the laws and expert food systems that the institutional environment claims.

Keywords: Agro-food markets. Artisanal cheeses. Informality. Southwest of Paraná. Regional development.

\section{Mercados de las agroindustrias familiares de queso artesanal del Sudoeste de Paraná}

\section{Resumen}

Este trabajo quiere entender por qué las agroindustrias familiares de quesos artesanales que producen bajo un sistema estatal de inspección formal nominado: SIM (Sistema de Inspección Municipal) - venden la mayor parte de la producción en el mercado informal. Para lograr este objetivo, entrevistamos a seis productores familiares de queseros en la región Sudoeste de Paraná, en el año 2015. Los resultados y conclusiones revelan un conjunto variado y multidimensional de elementos que simultáneamente actúan sobre las experiencias y estructuran los mercados locales e informales. Los agricultores tratan de eludir las reglas de los sistemas de servicio de alimentos y construir estrategias de desarrollo regional más autónomas en respuesta al llamado de los consumidores a mantener las características artesanales de los quesos vendidos en el mercado de cadena corta. Por otro lado, también tratan de alejarse del Estado, en la medida en que, incluso si son formales bajo el sistema de inspección del Estado, buscan la construcción social de sus mercados fuera de las leyes y los sistemas de alimentos expertos que el entorno institucional reclama.

Palabras-Clave: Mercados agroalimentarios. Quesos artesanales. Informalidad. Sudoeste de Paraná. Desarrollo regional.

\section{Introdução}

O sistema agroalimentar prevê que os alimentos sejam processados conforme as regras estabelecidas pelas instituições e sistemas peritos do Estado (GIDDENS et al., 1997). Para Ploeg (2008) isso beneficia as grandes indústrias, redes de varejo e empresas que comercializam os alimentos mundialmente. Essa forma de proceder do Estado e da legislação alimentar procura incentivar historicamente um 'modelo' de produção-distribuição-consumo de alimentos em grande escala, com mercados oligopolizados e formalizados, cadeias longas de abastecimento e alimentos cada vez mais processados. Além disso, através de estratégias de marketing e das tecnologias da informação e comunicação, estes mercados procuram 'moldar' preferências e transmitir confiança aos consumidores para construir seus mercados (BAUMAN, 2008; LANG e HEASMAN, 2004; PORTILHO, 2009).

Entretanto, estes mercados não são os únicos na circulação de alimentos. Quando analisados as estratégias de comercialização usadas pelos agricultores familiares, percebe-se a existência dos chamados 'mercados alternativos' (GAZOLLA e SCHNEIDER, 2017). Segundo Schneider (2016) há quatro grandes 'tipos' de 
mercados na agricultura familiar: os de proximidade social, locais e territoriais, convencionais e os públicos e institucionais. Segundo o autor, o que os distingue são os dispositivos de regulação, controle e governança dos mercados que poderiam levar os agricultores familiares em direções. Essencialmente, os agricultores seriam colocados frente a uma dualidade básica nestes quatro mercados: autonomia $\mathrm{x}$ dependência.

Nas iniciativas investigadas neste trabalho, os agricultores familiares que possuem agroindústrias de queijos artesanais estão muito próximos às características do primeiro 'tipo ideal' de mercados propostos por Schneider (2016), devido os mercados serem construídos por relações sociais e espaciais de proximidade entre atores (agricultores e consumidores). Segundo Gazolla (2013), diferente de uma grande indústria, as agroindústrias familiares (AGFs) são gerenciadas por famílias que se utilizam de diferentes conhecimentos para produzir e comercializar seus alimentos; além de possuírem características como a produção em pequena escala, o autocontrole da família sobre os insumos necessários, agregação de valor sobre as próprias matérias primas produzida nas propriedades e a comercialização em cadeias curtas agroalimentares.

Muitas atividades agroindustriais fazem parte da vida dos moradores do meio rural brasileiro informalmente, sem registro de produção de acordo com as normas higiênico-sanitárias. Del Grossi e Silva (2002) já haviam constatado que dentro desse quadro de informalidade, as agroindústrias não possuíam perspectivas de desenvolvimento. Produzir informalmente é, muitas vezes, uma opção das famílias dos espaços rurais, pois as estratégias produtivas e comerciais são variadas e estar em situação de informalidade não limita, necessariamente, a reprodução social das famílias. Por um lado, a informalidade nos mercados deixa muitas agroindústrias na invisibilidade social, mas, por outro, estão agindo estrategicamente e localmente, seguindo caminhos próprios de busca de autonomia e usando da 'margem de manobra' que os atores sociais possuem para 'driblar' as regras dos sistemas peritos de fiscalização alimentar (GIDDENS et al., 1997; LONG, 2006; PLOEG, 2008).

Neste contexto, estão as agroindústrias familiares de queijos artesanais no Brasil. Chalita (2012) afirma que há um grande potencial sem ser explorado, sendo que a diversidade de produtos, diversidade regional de iniciativas e práticas, complexidade de culturas e a qualidade de sabores dariam ao país grande prestígio na comercialização de queijos, bem como outros derivados obtidos a partir do leite. Ao processar a matéria prima, é possível também, aproveitar melhor a força de trabalho existente nas unidades produtivas como no caso de mulheres, jovens e até idosos (DEL GROSSI e SILVA, 2002). Existem famílias com disponibilidade de força trabalho além das atividades desenvolvidas, isso porque a área de terras é pequena e as atividades realizadas limitadas. Por exemplo, muitos jovens buscam oportunidades de trabalho nas cidades próximas, perdendo os laços com a agricultura familiar. Com a existência da agroindústria familiar esse cenário pode ser alterado, pois a atividade de transformação dá oportunidades aos jovens de permanecer no campo.

Neste sentido, a produção e comercialização dos queijos seria uma alternativa de desenvolvimento regional, pois beneficiaria as matérias primas dos agricultores, agregando valor, gerando renda e assegurando que os mesmos e suas famílias pudessem manter-se nos espaços rurais. Além disso, como os mercados de queijos 
artesanais são mercados de proximidade social e espacial, oportuniza a demanda dos consumidores que são sensíveis às características de qualidade multidimensional que estes possuem (NIEDERLE, 2013), assegurando a compra das quantidades produzidas pelos agricultores e satisfazendo seus hábitos de consumo, já que procuram por alimentos diferenciados e feitos de forma artesanal (CRUZ e MENASCHE, 2011; GAZOLLA, 2013).

Neste sentido, o trabalho objetivou entender o porquê de agroindústrias familiares que produzem o queijo artesanal, mesmo que credenciadas no Sistema de Inspeção Municipal (SIM), vendem a maior parte da sua produção nos mercados informais e de proximidade social e espacial (são cadeias curtas de abastecimento local/microrregional).

O presente artigo está dividido em quatro seções, além desta introdução e das considerações finais. Na primeira se apresenta a metodologia da investigação e uma síntese dos dados secundários obtidos no IBGE sobre a agroindústria rural no Paraná para demonstrar a importância produtiva e mercantil da atividade. Na segunda seção, sintetiza-se uma literatura sobre agroindústria familiar e de estudos dos mercados de proximidade social e espacial. Finalmente, na terceira e quarta, analisa-se os dados primários da pesquisa de campo e as evidências que condicionam à dinâmica e funcionamento dos mercados informais das agroindústrias familiares.

\section{Metodologia da investigação}

Para levantar dados sobre os mercados das agroindústrias queijeiras e a opinião dos atores sociais em relação aos órgãos de regulamentação do Estado. A pesquisa buscou estudar seis casos de produção de queijo colonial, alocadas em quatro Municípios do Sudoeste do Paraná. Todas as unidades produtivas investigadas possuíam áreas de terra entre 5 e 29 ha. Na Figura 1 é possível localizar esses municípios (Santa Izabel D'Oeste, Itapejara D'Oeste, Chopinzinho e Francisco Beltrão) identificados com pontos verdes.

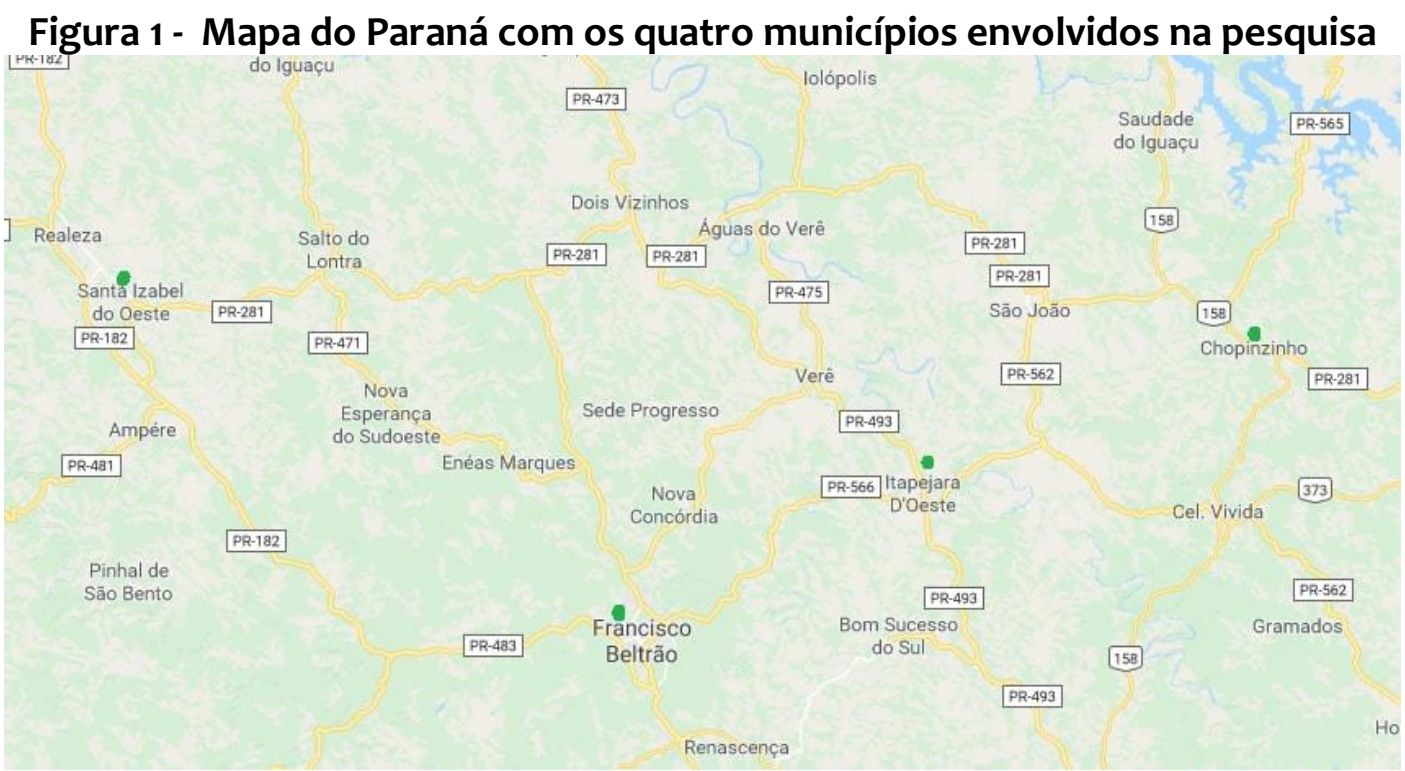

Fonte: Google Maps (2017). Adaptado pelos autores. 
Salienta-se que a pesquisa foi qualitativa com o estudo de multicasos. Propôsse a investigar seis diferentes experiências de agroindústrias familiares (com produção de queijos artesanais) no Sudoeste do Paraná, no ano de 2015. Os casos estudados foram escolhidos por serem referência na produção de queijos na região. Os casos investigados estão formalizados, atendendo o que dispões as regras do Sistema de Inspeção Municipal (SIM).

Foram aplicadas seis entrevistas semiestruturadas com as famílias pesquisadas. As mesmas foram gravadas e, posteriormente, degravadas e realizado análise de conteúdo. Trechos essenciais das falas dos atores sociais presentes nas entrevistas foram utilizados como evidências científicas ao longo do texto. Além disso, a partir das entrevistas se conseguiu captar outras variáveis e indicadores que foram úteis a construção de algumas das ilustrações que estão presentes ao longo do trabalho. O diário de campo também foi utilizado como ferramenta metodológica auxiliar para captar os processos sociais em torno dos mercados das agroindústrias. Quantitativamente, os dados do IBGE, especificamente, os da variável agroindústria rural, que estão no Censo Agropecuário de 2006 (última atualização de 2012 realizada pelo IBGE), disponíveis no Sistema de Recuperação Automática de Dados (SIDRA) foram mobilizados para evidenciar a importância das AGFs no Paraná.

Na sequência, apresenta-se uma breve descrição dos seis casos investigados de forma a caracterizá-los. O Primeiro caso se refere a uma família, onde os avós ainda residem na mesma propriedade em companhia do filho, nora e netos. Na propriedade os alimentos produzidos são leite, hortaliças e queijo. O queijo ocupa 10\% do leite produzido e os diferentes tipos de alimentos são comercializados nos mercados locais. O segundo caso, o casal fundador da queijaria e também seu filho e nora residem na unidade de produção e estão envolvidos na atividade. A família produz leite para comercialização in natura e também produz queijos; 50\% da produção de leite é transformada em diferentes tipos de queijos que circulam em diversos mercados. Ainda são comercializados outros produtos resultantes da produção como nata, ricota e os suínos que são alimentados com soro.

No terceiro caso, o casal tem dois filhos e durante a trajetória histórica dividiram o tempo de trabalho entre a lavoura (produção de milho, soja, trigo, aveia) e a produção diversificada de queijos. $O$ filho mais jovem escolheu seguir na produção vegetal e a filha escolheu seguir na produção de queijo. Toda a produção de leite é transformada em queijo. O quarto caso é de uma família com o casal e um filho pequeno, de apenas sete anos. A família gerencia uma pousada rural, onde são comercializados galinhas e ovos caipiras, hortaliças, leite, queijo, doces e geleias de frutas e massas. A queijaria produz dezesseis tipos de queijos, além de manteiga, nata, doce de leite e requeijão. Do leite obtido, $80 \%$ é utilizado na fabricação dos queijos, o restante é destinado à produção de massas, outros derivados e consumo familiar.

No quinto caso a família é composta por um casal com duas filhas pequenas e os avós paternos. A agroindústria ainda não tem sucessor, as filhas mais jovens ainda possuem menos de 3 anos. De início o queijo era somente para o autoconsumo da família e depois foi se consolidando como uma nova atividade econômica. Um membro da família passou vinte dias em Turim (Itália) aprendendo técnicas para a produção de queijos artesanais, país em que a maioria dos queijos são elaborados desta forma. Neste caso, $99 \%$ do leite é transformado em queijo, o restante é para 
autoconsumo familiar. O sexto caso é de um casal com três filhos, onde um dos rapazes será o sucessor na agroindústria familiar. A família passou a produzir queijo frente à necessidade de ampliar a produção e a renda, fazendo parceria de trabalho com uma família vizinha. Ambas as famílias produzem queijo, com características e rebanhos diferentes dentro da mesma queijaria. A família ainda comercializa batata, mandioca, nata, ovos, manteiga e suínos alimentados com soro. Aproximadamente $70 \%$ do leite é transformado em queijo.

\section{Mercados e agroindústrias familiares}

Segundo Wilkinson (2008) as agroindústrias familiares são unidades de produção que contam com o processamento de alimentos com a finalidade de comercialização dos mesmos em mercados de proximidade social. Mior (2007, p. 10) define agroindústria pelos procedimentos realizados na propriedade rural, onde os indivíduos "produzem, processam e/ou transformam parte de sua produção agrícola e/ou pecuária, visando, sobretudo, a produção de valor de troca que se realiza na comercialização".

Gazolla (2013) também apresenta cinco elementos que definem as agroindústrias familiares e comtemplam suas principais características: i) a forma familiar com que os alimentos são produzidos e a ação proativa dos agricultores na gestão e trabalho desenvolvido; ii) a produção em pequena e média escala de alimentos com qualidades diferenciais e inovações embutidas; iii) autocontrole dos recursos materiais (trabalho familiar, terras, autoconsumo, animais, etc.) feita pelas famílias; iv) agregação de valor (econômico, social e territorial) sobre a matéria prima resultante da propriedade e; v) o acesso aos mercados locais ou de proximidade em função da fidelidade dos consumidores, que é mantida por relações pessoais.

As agroindústrias podem ser familiares ou compartilhadas por um grupo comunitário, associação, grupo de mulheres e/ou de famílias vizinhas/com parentesco. A autonomia da produção é uma das bases sociais desta atividade, uma vez que todos os integrantes detêm conhecimentos sobre o processo produtivo no seu todo e possuem participação efetiva na tomada de decisões. As mulheres estão diretamente ligadas ao processo produtivo e a comercialização, alcançando maior autoestima por passarem a participar ativamente da sociedade. Os cursos de aprimoramento também são oportunidades para o público feminino que antes não acessava conhecimentos com frequência. Nas agroindústrias compartilhadas as mulheres ainda dividem as tarefas e o tempo de trabalho nas atividades agroindustriais e tempos livres para laser e descanso (MIOR, 2008).

A escala de produção não é o principal objetivo a atingir, no entanto as exigências para o controle sanitário da qualidade, muitas vezes, impõem aos agricultores a necessidade de produção em escalas maiores (MALUF, 2004). Nas agroindústrias a comercialização está fortemente relacionada com a qualidade multideterminada e multidimensional dos alimentos, não sendo interessante a produção em grandes quantidades, por ser este um limitante à manutenção dos aspectos de qualidade da produção artesanal (NIEDERLE, 2013).

A tecnologia utilizada está muito mais atrelada aos conhecimentos repassados por gerações do que na infraestrutura necessária. Poucos equipamentos são necessários e na sua maioria são utilizados nas "cozinhas" regionais, de forma a 
não necessitar de uma grande estrutura voltada ao processamento. No entanto, o produto artesanal não é considerado por Silveira e Heinz (2005) como de baixa tecnologia, pois os conhecimentos necessários para produzir com qualidade multidimensional são vultuosos. Estes são alguns motivos pelos quais o modo de controle de qualidade vigente (sistema perito higiênico-sanitário do Estado) não corresponde à realidade observada na produção agroindustrial artesanal.

Os alimentos são resultado do beneficiamento de matéria prima da unidade de produção, potencializando à produção local e promovendo a cultura e os costumes alimentares da população. A matéria prima é responsável pela qualidade dos produtos e também garante uma maior margem de renda aos agricultores, sendo uma vantagem competitiva para o controle de qualidade e para a sobrevivência econômica das agroindústrias. O resultante das agroindústrias são alimentos de qualidade, que remetem ao uso ecológico dos recursos naturais, produção limpa, reaproveitamento de subprodutos e lembranças da infância e do rural (WAQUIL et al, 2013). Ainda segundo o autor antes mencionado, os consumidores possuem interesse pelos alimentos (atribuindo um valor subjetivo diferentemente dos produtos das grandes agroindústrias), logo as relações sociais de proximidade e interconhecimento acontecem intensamente.

Através das relações sociais próximas vão surgindo e se consolidando novos mercados para as agroindústrias familiares. Abramovay (2004) explica que a abordagem sociológica dos mercados procura compreendê-los como resultados concretos da interação social; assim, as formas e dinâmicas de funcionamento que os mercados vão adquirindo, ao longo dos anos, dependem da força, organização, poder e recursos dos atores sociais. É assim que as agroindústrias constroem seus próprios mercados e criam suas estratégias dentro de realidades sociais específicas, enraizadas em territórios com características próprias.

Devido aos mercados serem criados por meio das relações sociais é que os agricultores informais (aqueles que não estão devidamente alinhados com a legislação alimentar e seus sistemas peritos inerentes) garantem seus espaços de comercialização. Entretanto, essa estratégia produtiva depende, também, das relações de confiança. Os consumidores relacionam confiança com a figura do agricultor e passam a reconhecer os seus produtos como sendo de qualidade, fazendo aquisição dos mesmos e até voltando a comprar com certa frequência (WILKINSON, 2002; 2008; NIEDERLE, 2013).

A renda é acrescida nesse processo, de modo a garantir os gastos em geral, na maioria das vezes, os gastos mensais (produtos essenciais, alimentos, energia elétrica, água e gás), gastos que conferem melhorias para a família (roupas, calçados, produtos de higiene e perfumaria, viagens, entre outros) e investimentos para a manutenção da própria agroindústria (compra de equipamentos, investimento em embalagens e rótulos, aquisição de veículos para distribuição, entre outros).

A qualidade de vida das famílias envolvidas é melhorada, possibilitando o acesso a mais bens de consumo e serviços diferenciados, satisfação pessoal e lazer. Nesse sentido, o desejo de permanecer no meio rural se sustenta por gerações, garantindo a reprodução da cultura, dos alimentos fabricados, da economia local e contribuindo para a redução dos problemas causados pelos grandes aglomerados de pessoas nos centros urbanos. A sustentabilidade está naturalmente associada ao processo produtivo das agroindústrias. Ser sustentável remete a ideia de um 
processo dinâmico e durável, que possibilita o crescimento econômico, promove a justiça social, preservando as culturas locais, recuperando e preservando o meio ambiente constantemente. Os resíduos gerados nas agroindústrias são reutilizados no próprio sistema, seja como alimento, adubo ou outra finalidade. Logo, o ciclo é natural, não agride o meio ambiente e garante trabalho e renda para as famílias, que por sua vez contribuem para os mercados e economias locais (PREZOTTO, 2002).

A organização das agroindústrias em grupos, associações, cooperativas, ou seja, em redes proporciona maior estabilidade das vendas, fidelização dos consumidores, impacto sobre o comércio local, possibilidade de agregação de conhecimentos (por meio de cursos técnicos coletivos, palestras, encontros de aprendizagem), facilidades na aquisição de insumos por meio das compras coletivas, maior estabilidade financeira e facilidades de acesso ao processo de formalização (GAZOLLA, 2013).

De maneira contraditória, a produção formal, que garante novos mercados e geração de renda em maior escala, está sendo negada por alguns agricultores familiares. Isso porque a legislação exige determinadas mudanças e adequações do sistema agroindustrial que não são aceitas pelos agricultores, que não querem adaptar seus meios de produção tradicionais/artesanais (GIDDENS et al., 1997; LONG, 2006). As agroindústrias são fiscalizadas conforme as legislações agroalimentares e seus sistemas peritos. Por exemplo, na produção de queijo é necessária a pasteurização do leite ou a comercialização após 60 dias de maturação para estar de acordo com a legislação sanitária (além de outras adequações de estrutura, higiene e formas de produção) seja ela municipal, estadual ou federal.

O modo como foram construídos os regramentos desrespeita as formas artesanais como são elaborados os queijos e impõem um produto para a comercialização diferente da preferência dos mercados consumidores. O discurso imposto e/ou instituído pelos sistemas peritos são tidos como a única verdade, sem ajustes, que possam viabilizar e valorizar as produções artesanais (CRUZ e MENASCHE, 2011). Os agricultores informais mantêm os produtos tipicamente artesanais, sendo estes os mais suscetíveis à extinção por conta das regras que envolvem a fabricação de alimentos (DORIGON, 2010). Este último autor, afirma que a informalidade ocorre pela dificuldade de encontrar meios para a legalização (infra estrutura, capital, dificuldade com assistência técnica, etc.), além disso, ressaltou que a maior dificuldade em formalizar as agroindústrias é aceitar as transformações que o alimento terá que sofrer depois da formalização, tendo em vista as mudanças do modo de fabricação (características de sabor, odor, cor, significados, padronização, entre outros).

Neste sentido, Wilkinson (2002) divide as forças relacionadas à produção agroalimentar como pertencentes de dois extremos (o mundo industrial, buscando a produção em escala e o mundo artesanal, baseado na tradição e confiança). Portanto, buscar qualificar e certificar dois 'modelos' tão distintos da mesma maneira é, certamente, incompatível com a realidade e passível de erros graves com o desenvolvimento regional das iniciativas. Dorigon (2010) caracterizou os produtores de queijo, da região Oeste de Santa Catarina, como os mais pobres, com menos contato com o mundo da ciência e pouco articulados com outros atores sociais; um público produtor de alimentos altamente fragilizado e com risco de ficar à margem da sociedade. Sendo assim, a produção de alimentos diversificados, diferenciados e 
com significados próprios de localidade, cultura e história estão dependendo de atitudes e ações governamentais que respeitem os agricultores e, também, os hábitos de consumo dos consumidores que querem acessar estes alimentos.

A forma artesanal de produzir se diferencia da metodologia técnica utilizada pelas grandes indústrias que visam o ganho em escala. Neste sentido, políticas com falta de clareza conceitual, resultam em ações do poder público e comportamento dos serviços de apoio técnico ou gerencial que tratam como homogêneo um universo heterogêneo, com efeitos sociais e econômicos diferentes dos pretendidos (SILVEIRA e GUIMARÃES, 2007). O toque especial que cada produtor dá ao seu produto é o diferencial do artesanal, o que faz cada alimento único (SILVEIRA e HEINZ, 2005). O valor dos queijos artesanais é mais do que uma simples margem econômica por unidade, envolve a tradição, o saber fazer do artesão, a cultura, as especificidades do local e os significados ecológicos e sustentáveis associados.

Por um lado, a construção social dos mercados se faz por meio de contratos de compra e venda, em muitos casos informais, pois são baseados em teias de relações sociais, confiança e interconhecimento entre atores sociais (consumidores e agricultores), especialmente em canais de comercialização curtos (GAZOLLA e SCHNEIDER, 2017). Neste caso, os atores sociais criam normas próprias que orientam como os mercados vão funcionar. De outro lado, as instituições são decisivas na formatação e conformação de regras ao funcionamento dos mercados. Segundo Mattedi (2005), as instituições determinam a ação dos atores, pois orientam a ação dos mesmos a partir de um arcabouço jurídico e de regulamentos institucionais. Assim, as instituições regem as regras da tradição, da moral, do direito e guiam os indivíduos para agir conforme as 'coordenadas' delas emanadas. No primeiro processo social, têm-se mercados mais informais e, no segundo, os mercados regulados pelas legislações alimentares do Estado brasileiro, em vários níveis (sistemas peritos municipais, estaduais e federais).

No caso das agroindústrias familiares estudos têm evidenciado que os atores sociais possuem agência para delinear suas estratégias mercadológicas de acordo com as suas possibilidades, isso porque não conseguem alterar o regime sociotécnico dominante na produção e consumo de alimentos (LONG, 2006). O objetivo dos agricultores que possuem agroindústrias familiares é conseguir o máximo de controle sobre os recursos que são necessários para sua reprodução social. Também visam construir mercados que lhes possibilitem exercer sua agência, obter rendimentos necessários e poder controlá-los constantemente e autonomamente (GAZOLLA e PELEGRINI, 2011). Portanto, a construção dos mercados é resultado de ações específicas, enraizadas e socialmente determinadas de interação social (ABRAMOVAY, 2004). A forma como essa ação social se dá é digna de ser estudada, haja vista a complexidade de seus fatores determinantes.

Por fim, nesta seção, discutem-se alguns dados do IBGE, sobre a agroindústria rural, para o estado do Paraná e suas dez microrregiões, de modo a evidenciar a importância produtiva e dos mercados das agroindústrias. Na Tabela 1 é possível notar que regionalmente, no estado do Paraná, as agroindústrias rurais estão presentes mais proeminentemente na Região Sudoeste do PR com 31,55\% dos valores da produção gerados. Isso significa que quase uma em três agroindústrias existente no estado estão alocadas espacialmente nesta mesorregião, justificando a 
pertinência de estudo desta atividade de elaboração e processamento agroalimentar.

Tabela 1 - Valores da produção da agroindústria rural nas mesorregiões do Paraná

\begin{tabular}{c|c|c}
\hline Mesorregiões homogêneas do Paraná & $\begin{array}{c}\text { Valor da produção } \\
\text { (x mil reais) }\end{array}$ & $\begin{array}{c}\text { Valor da produção } \\
(\%)\end{array}$ \\
\hline Sudoeste Paranaense & 21.963 & 31,55 \\
Oeste Paranaense & 11.855 & 17,03 \\
Metropolitana de Curitiba & 7.442 & 10,69 \\
Norte Central Paranaense & 6.850 & 9,84 \\
Norte Pioneiro Paranaense & 5.195 & 7,46 \\
Centro-Sul Paranaense & 5.022 & 7,21 \\
Sudeste Paranaense & 4.361 & 6,26 \\
Noroeste Paranaense & 2.856 & 4,10 \\
Centro Oriental Paranaense & 2.816 & 4,04 \\
Centro Ocidental Paranaense & 1.250 & 1,79 \\
\hline Paraná (total) & 69.609 & 100,00 \\
\hline
\end{tabular}

Fonte: IBGE (Censo Agropecuário, 2006). Dados da última atualização realizada pelo IBGE, em 2015.

A Tabela 2 apresenta os dados dos valores da produção da agroindústria rural para todo o estado do Paraná. É possível notar que o alimento em análise neste trabalho, os queijos, são o principal alimento fabricado pelas experiências com 24,04\% dos valores da produção (o IBGE considera queijo e requeijões). Este alimento perfaz quase $1 / 4$ de tudo o que é produzido pelas agroindústrias rurais do Paraná, evidenciando a importância de se compreender melhor estas iniciativas dos agricultores e os mercados que são construídos para a venda deste alimento.

Tabela 2 - Valor da produção da agroindústria rural no Paraná.

\begin{tabular}{c|c|c}
\hline \multirow{2}{*}{ Produtos da agroindústria rural } & \multicolumn{2}{c}{ Variável } \\
\cline { 2 - 3 } & $\begin{array}{c}\text { Valor da produção } \\
\text { (mil reais) }\end{array}$ & $\begin{array}{c}\text { Valor da produção } \\
(\%)\end{array}$ \\
\hline Queijo e requeijão & 16.733 & 24,04 \\
Carne de bovinos (verde) & 9.643 & 13,85 \\
Carne de suínos (verde) & 7.722 & 11,09 \\
Carvão vegetal & 4.897 & 7,03 \\
Produtos de madeira & 4.256 & 6,11 \\
Aguardente de cana & 4.195 & 6,03 \\
Vinho de uva & 3.948 & 5,67 \\
Carne de outros animais (verde) & 3.237 & 4,65 \\
Embutidos (linguiças, salsichas) & 2.469 & 3,55 \\
Pães, bolos e biscoitos & 2.255 & 3,24 \\
Café torrado em grão & 1.899 & 2,73 \\
Farinha de mandioca & 1.375 & 1,98 \\
Arroz em grão & 1.163 & 1,67 \\
Rapadura & 1.111 & 1,60 \\
Melado & 1.043 & 1,50 \\
Café torrado e moído & 839 & 1,21 \\
Doces e geleias & 438 & 0,63 \\
Fumo em rolo ou corda & 394 & 0,57 \\
Sucos de frutas & 385 & 0,55 \\
\hline
\end{tabular}




\footnotetext{
Total 69.609

Fonte: IBGE (Censo Agropecuário, 2006).

Nota: Dados da última atualização realizada pelo IBGE, em 2012. Os produtos com valores menores de $0,5 \%$ não estão contidos na tabela, devido ao tamanho que a mesma ficaria.
}

Além do queijo, outros alimentos estão sendo produzidos pelas agroindústrias familiares paranaenses (Tabela 2), estudar os meios pelos quais as famílias estão viabilizando as suas produções permite conhecer e aprimorar processo de produção e distribuição de alimentos no Paraná. As agroindústrias possuem importante participação quantitativa na produção de alimentos, geração de renda e fornecimento de alimentos artesanais no estado.

\section{Mercados construídos socialmente pelas agroindústrias familiares}

Todos os entrevistados relataram não terem tido problemas com a fiscalização ou legalização quando se encontravam informais, isso porque a demanda por queijo é vasta, sempre possuindo comércio para toda a produção, o que corrobora com a visão de Dorigon (2010). O queijo colonial apresenta características próprias e exclusivas (sabor, consistência, coloração, odor, significados no tocante a sustentabilidade) que constituem vantagens competitivas nos mercados (MIOR, 2007, SILVEIRA e HEINZ, 2005). Além disso, a relação de fidelidade entre produtores e consumidores garante a comercialização dos alimentos artesanais. Alguns trechos das entrevistas comprovam essa questão junto aos agricultores:

ah, eles (consumidores) falam que é queijo de qualidade, é diferente né. (Entrevistado 2, Itapejara D'Oeste, 2015). A gente leva na feira e vende tudo, tudinho mesmo. Às vezes, falta queijo ainda (Entrevistado 1, Francisco Beltrão, 2015).

Os relatos evidenciam a comercialização por meio de cadeias curtas, processo pelo qual os agricultores e os consumidores mantêm uma relação direta. Segundo Gazolla e Schneider (2017) estes mercados funcionam como redes agroalimentares alternativas, no sentido que se distinguem dos mercados de commodities, dos hierarquizados e da integração agroindustrial com grandes empresas. O que estrutura estes mercados são as relações de proximidade social e geográfica entre agricultores e consumidores, em que atributos como confiança, interconhecimento, trocas frequentes e contratos informais, entre outros, fazem com que estes mercados funcionem e sejam vantajosos e viáveis social e economicamente para os dois lados da 'equação' (para produtores e consumidores).

A Figura 2 apresenta os mercados construídos para as seis experiências de agroindústrias pesquisadas. Observa-se que todas as seis agroindústrias comercializam a sua produção de queijos através de cadeias curtas, indo desde o tipo face a face (na casa do agricultor, na agroindústria, entrega na casa dos consumidores, feiras), até mercados locais e regionais (é o caso dos supermercados, PNAE, panificadoras, alguns intermediários). Em nenhuma das experiências investigadas os alimentos percorrem grandes distâncias geográficas (para fora da região de origem) e, tão pouco, desenraizam-se socialmente dos laços e redes sociais de produção-consumo (MARSDEN et al., 2000; RENTING et al., 2003). 


\section{Figura 2. Mercados construídos pelas agroindústrias familiares para comercialização dos queijos.}

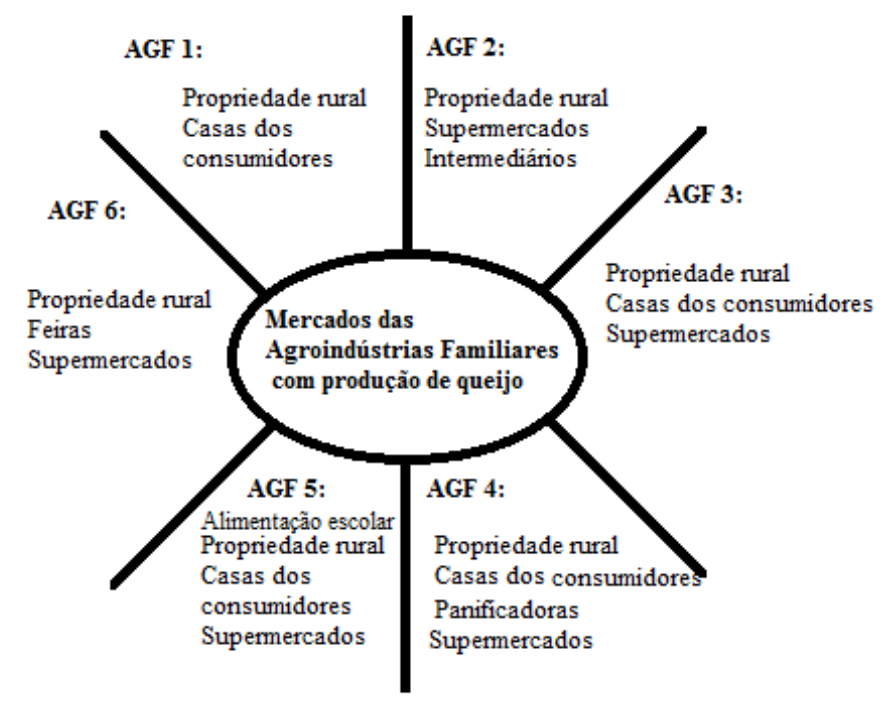

Fonte: Pesquisa de campo (2015).

Estas iniciativas de agregação de valor iniciaram de forma tímida e com o passar dos anos foram se desenvolvendo, sendo que as seis queijarias saíram da informalidade e passaram a atender as normativas da legislação alimentar, especificamente, do SIM, o que garantiu o acesso a novos mercados. Com a formalização, novos equipamentos e práticas produtivas foram sendo inseridas nas agroindústrias. Os agricultores apontaram algumas melhorias proporcionadas pelo SIM, especialmente para o acesso a novos mercados.

\footnotetext{
Nossa, o SIM ajudou bastante na venda, porque quem compra sabe que é queijo... tudo certinho né (Entrevistado 1, Francisco Beltrão, 2015). Depois que a gente conseguiu o SIM a gente viu que o negócio ia longe, começamos vender pra mais mercados né, além da feira e das casas tinha os mercados também, a produção aumentou. Compramos mais equipamentos e fomos aumentando até que dava (Entrevistado 5, Francisco Beltrão, 2015).
}

Atualmente, todos afirmam que tudo o que é produzido é comercializado sem muito esforço e somente com a famosa propaganda feita no modo "boca a boca", pelo 'marketing' dos consumidores que compram o alimento e falam para outros consumidores, amigos, parentes e vizinhos. A qualificação multidimensional dos alimentos artesanais garante uma comercialização regular porque os consumidores atribuem significados relacionados a lembranças da infância, sustentabilidade, alimentos saudáveis, entre outros (SILVEIRA e HEINZ, 2005; NIEDERLE, 2013).

No tocante à coloração, sabor, odor, todos relembraram algumas alterações que ocorreram ao longo dos anos, mas afirmaram que com o tempo conseguiram melhorar suas técnicas de elaboração e superar problemas técnicos e de processamento dos queijos. Apenas um dos entrevistados afirmou ter enfrentado problemas com coliformes fecais em análises realizadas, o mesmo atribuiu como 
fator determinante os dias chuvosos, em que a água utilizada fica contaminada pelos dejetos dos animais.

As famílias perceberam que pasteurizar o leite para a produção de queijos estava diminuindo a qualidade dos queijos artesanais, assim, os queijeiros como são popularmente chamados, começaram a 'driblar' as regras do sistema de inspeção e produzem queijos artesanais de forma inovadora (sem pasteurização do leite), similarmente as famílias/agroindústrias que estão em condição de informalidade nos mercados.

Na Tabela 3 é possível verificar a produção anual de queijos vendida por cada família estudada, com leite pasteurizado e com leite cru. Observa-se que a produção de queijo artesanal feito com leite cru é de $38.040 \mathrm{~kg} / \mathrm{ano}$, o que corresponde a quase $60 \%$ da quantidade colocada nos mercados ( $58,37 \%$ exatamente) em relação ao total de queijo produzido e comercializado. Já a produção com leite pasteurizado e formal foi de $27.120 \mathrm{~kg} / \mathrm{ano}$, o que compreende cerca de $40 \%$ da produção colocada nos mercados (41,62\%). 
Tabela 3 - Valor total da produção anual de queijos com leite pasteurizado e com leite cru nas famílias estudadas.

\begin{tabular}{c|ccccc}
\hline \multirow{2}{*}{$\begin{array}{c}\text { Agroindústrias } \\
\text { familiares }\end{array}$} & \multicolumn{4}{|c}{ Quantidades produzidas/comercializadas de queijo } \\
\cline { 2 - 5 } & \multicolumn{2}{|c|}{ Queijo com leite pasteurizado } & \multicolumn{2}{c}{ Queijo com leite cru (artesanal) } \\
\cline { 2 - 6 } & Quantidade $(\mathrm{kg})$ & $\begin{array}{c}\% \text { em relação ao } \\
\text { total produzido }\end{array}$ & Quantidade (kg) & $\begin{array}{c}\text { \% em relação ao } \\
\text { total produzido }\end{array}$ \\
\hline Família 1 & 0,0 & 0,0 & 480 & 100 \\
Família 2 & 15.120 & 60,0 & 10.080 & 40 \\
Família 3 & 9.600 & 95,24 & 480 & 4,76 \\
Família 4 & 0,0 & 0,0 & 9.600 & 100 \\
Família 5 & 0,0 & 0,0 & 16.200 & 100 \\
Família 6 & 2.400 & 67 & 1.200 & 33 \\
\hline Total/Média & 27.120 & 41,62 & 38.040 & 58,37 \\
\hline
\end{tabular}

Fonte: Pesquisa de campo (2015).

Mesmo estando formalizadas através do SIM, três famílias (1, 4 e 5) preferem produzir apenas com leite cru e as outras três também produzem esse queijo tipo artesanal (a base de leite cru) em diferentes percentuais. É importante lembrar que a legislação permite a comercialização de queijos produzidos a partir do leite cru após 60 dias de maturação, mas não é o caso destas famílias, pois os queijos são vendidos antes do prazo estabelecido pelos órgãos de fiscalização.

\section{Por que os mercados são informais, se as agroindústrias são formais?}

Dos seis casos estudados, todos estão legalizados pelo SIM, cumprindo formalmente as exigências de inspeção e fiscalização dos alimentos para a elaboração dos queijos. Neste sentido, a grande pergunta de investigação que guiou a pesquisa foi entender o porquê a maior parte da produção destas unidades de produção formalizadas perante a legislação alimentar do Estado brasileiro, é comercializada e constrói mercados informais? Em outras palavras, com produção formal, por que a opção das famílias que possuem agroindústrias de queijos artesanais em vender as maiores quantidades dos alimentos pelos mercados não legalizados?

Para responder a questão da informalidade construiu-se o Quadro 1, em que são apresentados diferentes elementos e motivações dos agricultores familiares das seis famílias pesquisadas. Esse conjunto de informações ajuda a explicar os fatores (que são multifacetados e multideterminados) pelos quais a produção de queijos, mesmo sendo formal, circula predominantemente nos mercados informais construídos pelas famílias.

Um primeiro aspecto que chama a atenção é o que todos os entrevistados relataram que a formalização não foi tão 'positiva' e próspera conforme era esperado e que os alimentos resultantes da produção formal não agradam tanto o gosto dos consumidores. Há outros casos na literatura que já haviam relatado a não aceitação ou menor demanda de consumidores de leite e queijos provenientes de processos industriais e formais de processamento (pasteurização), que alteraria as principais propriedades nutricionais e de sabores dos alimentos, tornando o produto 'irreconhecível' por parte dos consumidores e até gerando desconfiança entre os mesmos (CRUZ e MENASCHE, 2011; COLETTI e PERONDI, 2015). 


\section{Quadro 1 - Motivos expressos pelas famílias que possuem agroindústrias que conduzem as experiências em direção aos mercados informais.}

\begin{tabular}{|c|c|}
\hline \multirow{12}{*}{$\begin{array}{c}\text { Motivos da } \\
\text { informalidade } \\
\text { institucional dos } \\
\text { mercados das } \\
\text { agroindústrias } \\
\text { familiares }\end{array}$} & Os produtores já possuem fidelização e a confiança dos clientes \\
\hline & $\begin{array}{l}\text { Comercialização é feita em cadeias curtas, sem a necessidade de comprovar a } \\
\text { qualidade e a entrega dos alimentos por meio de documentos }\end{array}$ \\
\hline & $\begin{array}{l}\text { Mercados já existentes e funcionais para comercialização mesmo estando em } \\
\text { condições de informalidade }\end{array}$ \\
\hline & Obtenção de alimentos de qualidade, mesmo sem seguir a legislação \\
\hline & Alto custo dos equipamentos necessários para a formalização \\
\hline & $\begin{array}{l}\text { Agroindústrias familiares trabalham com qualidade multidimensional e não } \\
\text { com qualidade higiênico-sanitária }\end{array}$ \\
\hline & $\begin{array}{c}\text { Incertezas sobre o futuro das agroindústrias e o processo sucessório na } \\
\text { unidade doméstica e de produção }\end{array}$ \\
\hline & $\begin{array}{l}\text { Baixa escala de produção em decorrência da pouca força de trabalho, baixa } \\
\text { escolaridade e pouco acesso aos conhecimentos científicos }\end{array}$ \\
\hline & $\begin{array}{l}\text { Dificuldade em elevar a escala de produção por conta do aumento de custos, } \\
\text { exigências de padronização dos alimentos e sobrecarga de trabalho dos } \\
\text { membros da família }\end{array}$ \\
\hline & Receio com endividamento das unidades de produção \\
\hline & $\begin{array}{l}\text { Aumento do custo de produção e consequente aumento do preço dos } \\
\text { alimentos comercializados }\end{array}$ \\
\hline & Necessidade de entrega regular e de não atender a demanda exigida. \\
\hline
\end{tabular}

Fonte: Pesquisa de campo (2015).

Inicialmente foi relatada uma realidade indicativa de desconformidades do sistema fiscal pelos agricultores. Alguns afirmaram que o SIM apenas observa se há o pasteurizador na agroindústria, mas não fiscaliza o uso do mesmo nos processos de elaboração dos alimentos. Os queijeiros afirmaram também que não utilizam o equipamento para todos os tipos de queijos, de acordo com a regra do SIM. Conforme os trechos de algumas entrevistas que evidenciam este processo social:

eles vêm aqui, fazem análise do queijo, sempre deu boa. Com ou sem pasteurizador não dá diferença nos testes. Mas a maioria das vezes eles só olham se o pasteurizador está ali, estando ali serve. O queijo não dá diferença mesmo (Entrevistado 3, Chopinzinho, 2015). A gente usa o pasteurizador pra uns tipos de queijo, mas o colonial mesmo não dá de usar. E não precisa mesmo, só estraga o queijo no gosto (sabor) (Entrevistado 4, Santa Izabel D'Oeste, 2015). Eu sempre aprendi com a mãe: o que a gente não quer pra gente, a gente não faz para os outros, o queijo é bom. Eu como, meus filhos, meu esposo, todo mundo come o queijo e nunca ninguém ficou doente (Entrevistado 6, Chopinzinho, 2015).

A pasteurização é o processo pelo qual o leite é condicionado à temperatura elevada por um determinado tempo $\left(62^{\circ}\right.$ a $68^{\circ}$ por 30 minutos, considerada a pasteurização lenta). Criado em 1850 com a finalidade de eliminar as formas de vida presentes, garantindo que o leite não se deteriore (CRUZ e MENASCHE, 2011). No processo de pasteurização o leite perde inclusive os microrganismos capazes de conferir sabor e qualidade diferenciada ao queijo, por esse motivo os queijeiros não utilizam o equipamento. Eles acreditam, com base nas suas experiências e conhecimentos tácitos, que a qualidade do queijo é elevada com o leite cru, assim como afirmam vários estudos já desenvolvidos no Brasil (AGNE, 2014; CRUZ e 
MENASCHE, 2011; DORIGON, 2010; MIOR, 2007; SILVEIRA E HEINZ, 2005; WILKINSON, 2002; WAQUIL et al, 2013).

Como as seis experiências investigadas evidenciam, em alguns casos, os parâmetros exigidos pela legislação alimentar não são essenciais para obter alimentos de boa qualidade e com segurança alimentar para os consumidores. Os agricultores familiares trabalham com qualidade multidimensional, na qual vários parâmetros de qualificação alimentar estão entrelaçados e imbricados socialmente nos alimentos produzidos (aspectos sociais, culturais, conhecimentos históricos, gastronômicos, de crença, ambientais, reputação, entre outros), não se restringindo ao parâmetro unilinear da legislação brasileira, que é o higiênico-sanitário, muito comum nas grandes indústrias de alimentos (PLOEG, 2008; NIEDERLE, 2013).

Os agricultores informais não adequam-se ao SIM, dentre outros motivos, porque não possuem os equipamentos obrigatórios, no entanto, aqueles que estão legalizados não seguem as normas do sistema como deveriam. Para a efetivação de políticas públicas adequadas ao desenvolvimento e a inserção das agroindústrias nos mercados formais a melhor ação seria a articulação de ações que promovam o desenvolvimento das agroindústrias de acordo com as necessidades individuais, sendo que a legalização pode não ser o ponto de partida para desenvolver as agroindústrias familiares (SILVEIRA e ZIMERMANN, 2004). Segundo o Quadro 1, exemplo dessa disparidade é o preço do pasteurizador, os entrevistados estimaram um valor em vinte mil reais ( $R \$ 20.000,00$ ), considerado por eles como um investimento elevado (aumento dos custos), uma vez que a produção é realizada em pequena escala (MALUF, 2004).

O modelo de fiscalização foi criticado pelos agricultores por não ser eficiente e por estar, em algumas ocasiões, 'freando' os processos de desenvolvimento regional das iniciativas. A qualidade exigida pelos fiscais é diferente da qualidade multidimensional proposta por Niederle (2013), que inclui nos aspectos de qualidade outras formas de qualificação que vão além da qualidade química, microbiológica e física. O primeiro deles é o aspecto ecológico (nível de degradação do ar e das águas, uso de químicos, destinação de resíduos). O segundo aspecto é o social (capacidade de incluir pessoas, construção de cidadania, melhoria da qualidade de vida). O resgate das tradições gastronômicas, no que diz respeito à alimentação define o aspecto cultural. E o quarto aspecto é o de aparência, este conquista o consumidor pela embalagem e pela beleza natural do produto, sem deixar de lado a conservação ideal dos alimentos.

As grandes indústrias de alimentos geralmente apresentam qualidade higiênico-sanitária, logo, a divulgação e a conscientização dos consumidores em relação aos aspectos descritos por Prezotto (2002) favorecem economicamente e socialmente os pequenos produtores que produzem queijo de forma artesanal e com qualidades diferenciadas. A qualidade dos alimentos das agroindústrias familiares envolvem diferentes aspectos qualitativos, desde o controle dos insumos de produção, a matéria prima que é produzida na própria unidade produtiva, passando pelos processos produtivos que envolvem cultura, conhecimentos e saber fazer dos agricultores, até características de sustentabilidade e regionalidade, por meio da preservação do ambiente, da paisagem e da cultura gastronômica local (NIERDELE e WESZ, 2009; GAZOLLA, 2013). 
Posterior a essa descoberta empírica relacionada à perda de qualidade do queijo pelas exigências dos órgãos de fiscalização, as famílias estudadas apontaram outras falhas que as deixaram sem confiança para enquadrarem-se, também, aos outros sistemas de inspeção (SIE e SIF). Essas falhas foram obstáculos no início da produção e podem estar motivando outras famílias a permanecerem nos mercados informais. Um dos fatores de especial relevância que impedem a adequação de agroindústrias informais é a incerteza sobre o futuro da queijaria. Os agricultores não tem certeza de que seus filhos adotarão a atividade queijeira para suas vidas, por isso aderir a outros sistemas de inspeção não foi uma expectativa observada em todas as famílias. Com a sucessão familiar incerta, novos e futuros investimentos precisam ser calculados e cautelosos (Quadro 1).

Mesmo favorecendo as famílias, proporcionando melhores condições de vida, os filhos ainda são jovens para decidir se no futuro continuarão a produção agroindustrial de queijo. Portanto, os benefícios das agroindústrias para os jovens rurais só serão confirmados em relação a sua permanência na atividade quando os mesmos atingirem a idade para tomar a decisão de permanecer na propriedade produzindo queijo ou seguir por outros caminhos. O relato de uma das mães entrevistadas explica claramente a situação descrita:

\footnotetext{
a gente não sabe ainda se algum filho vai querer continuar com a produção, então é complicado investir demais. Minhas meninas você viu, estão pequenas ainda e se elas escolherem outra coisa (profissão/ocupação) a gente vai deixar elas escolherem né, o que for melhor pra elas (Entrevistado 5, Francisco Beltrão, 2015).
}

Ao atender as adequações dos órgãos fiscalizadores, as agroindústrias familiares se sentem obrigadas a aumentar a escala de produção (Quadro 1). Algumas vezes, essa condição é favorável ao empreendimento, gerando renda, trabalho, inclusão social, acesso a informação e aos conhecimentos, a bens e serviços e ampliação dos mercados. No entanto, nem todas as agroindústrias possuem as mesmas ambições e necessidades. Existem agroindústrias que não estão aptas ao crescimento da escala produtiva. Isso porque essa escala, na maioria das vezes, não é a prioridade das famílias e, mesmo quando as unidades crescem, por fatores diversos (força de trabalho, espaço, tempo, matérias prima existente) são limitadas a uma determinada escala mínima de funcionamento (MALUF, 2004).

É importante ressaltar que cada agroindústria possui especificidades e, que dependem de ações que gerem desenvolvimento de formas diferenciadas. Os fatores limitantes para a elevação da escala de produção citados pelos entrevistados são força de trabalho na fabricação e comercialização, escolaridade e conhecimentos para acesso de novos mercados e controle financeiro, pouca disponibilidade de espaço nas propriedades para o pasto e os animais, pouca estrutura para aumento da criação e consequente cuidado excessivo que os produtores têm para não contrair dívidas, necessidade de elevar o preço do queijo comercializado e descaracterização do queijo artesanal. Estes fatores todos fazem com que, em muitas iniciativas, as agroindústrias optem por permanecer nos mercados informais e com menores escalas produtivas.

As famílias estudadas são pequenas, no máximo seis membros, mas que nem todos trabalham porque são idosos ou crianças. Logo, a característica de família rural 
se alterou ao longo dos anos e a força de trabalho está cada vez mais limitada. Além disso, a ocupação das pessoas com outras atividades (fora da unidade produtiva, com rendas não agrícolas) está cada vez mais presente na realidade dos agricultores, fato que reduz o número de pessoas envolvidas na produção de alimentos. Elevar a escala de produção de queijo significa elevar também a força de trabalho necessária para os cuidados com os animais (alimentação, ordenha, pastagem) fabricação e embalagem dos queijos, limpeza da agroindústria e comercialização, além de precisar comprar matéria prima e especializar e uniformizar o processo produtivo, bem como os alimentos fabricados (GAZOLLA, 2014).

Elevar a escala leva as famílias a descaracterizarem sua produção artesanal, tornando as agroindústrias mais próximas das grandes indústrias alimentícias, o que de um ponto de vista 'competitivo' nos mercados não é interessante para estas pequenas unidades agroindustriais artesanais. Além disso, quando o número de membros úteis ao processo produtivo é limitado, a produção também se torna limitada e, se não observar essa realidade o produtor corre risco de investir demasiadamente na contratação de força de trabalho sem obter retornos financeiros esperados, inviabilizando a atividade pelo aumento excessivo dos custos de produção (Quadro 1).

As unidades produtivas estudadas eram pequenas na sua extensão de território, a parte destinada à produção de leite e queijo em média era de 10 ha nos casos. Portanto, a criação de animais para produção de leite (criação com alimentação baseada no pasto, com pequenas complementações no cocho, pouca ração concentrada na dieta alimentar do rebanho) se limita ao espaço disponível e o aumento da produção resulta em mudanças na forma de produção de leite (o que retira características típicas do queijo artesanal) ou exige a compra ou uso de novas áreas (possibilidade refutada por todos os entrevistados). Os agricultores são extremamente cautelosos no uso do crédito, para ampliar as áreas de produção de matérias primas e animais, bem como na própria agroindústria familiar, pois todos relataram cautela em relação a novos investimentos na atividade, especialmente via financiamentos bancários (que pode os levar para um quadro de endividamento) (Quadro 1).

As normas apresentadas pelos agentes de formalização (para entrarem no SIE ou no SIF) incluem compra de equipamentos (pasteurizador, câmara fria, utensílios, entre outros), adequação do ambiente de produção (construção, pintura, revestimento), uso de embalagem (plástico filme, rótulo, entre outros) e alteração do transporte (caixas, refrigeração). As regras que dão acesso à formalidade também elevam os custos de produção, sendo assim os agricultores são obrigados a comercializar o queijo por um preço maior, que nem sempre é bem aceito pelos consumidores. Pelos relatos dos queijeiros, muitas vezes, o acesso aos mercados formais pode não ser lucrativo, se a venda for reduzida em decorrência do aumento dos níveis de preços. Mas essa é a visão dos agricultores entrevistados, em outros casos, os consumidores não deixam de consumir o queijo artesanal pelo preço, uma vez que estão mais interessados na qualidade multidimensional que os mesmos possuem.

Conforme Prezotto (2002) e Silveira e Heinz (2005) já evidenciaram em suas pesquisas a produção de queijo é um processo artesanal, a produção em escalas elevadas e por procedimentos que seguem normativas alimentares vigentes apenas 
diminuem o papel do queijeiro artesão. Deixando o alimento diferente, padronizado e sem tipicidade artesanal (CRUZ e MENASCHE, 2011; PREZOTTO, 2002). Esse aspecto, de dificuldade ao acesso a formalidade, foi unânime entre os produtores entrevistados. Todos alegaram que cada vez mais a legislação deseja um produto padronizado, deixando o saber fazer e a tradição à margem. Como consequência do processo, os agricultores visualizam os seus semelhantes e a si próprios como sendo dispensáveis futuramente e tem conhecimento de que a diversidade de produtos coloniais para venda será, em longo prazo, altamente reduzida, prejudicando principalmente as escolhas dos consumidores que terão uma "mesa" com alimentos cada vez menos diversos.

$\mathrm{O}$ acesso à formalidade e aos novos mercados, em muitos casos, dificulta a produção das famílias. A regularidade da entrega do produto final preocupa muitos pequenos produtores de queijo. O processo produtivo é delicado, exige condições ideais e nem sempre o queijo produzido atinge qualidade esperada em um tempo 'exato'. Além disso, as vacas que produzem o leite são animais sujeitos a doenças que podem reduzir a quantidade esperada da matéria prima para a industrialização. Em algumas semanas podem ser produzidas maiores quantidades e em outras menores quantidades do alimento. A garantia de entrega regular assusta muitos queijeiros que preferem permanecer na informalidade a correr o risco de não atender devidamente o novo grupo de consumidores (supermercados, programas do governo, pizzarias, restaurantes, entre outros).

A informalidade, como foi possível observar pelos casos estudados, tem suas vantagens e sua lógica na visão dos produtores de queijo. Dorigon (2010) afirma que quase todas as agroindústrias familiares iniciaram suas atividades informalmente, simplesmente porque os produtos antes de serem comercializados eram produzidos para o autoconsumo. As famílias em determinados momentos de sua trajetória, principalmente nos períodos de dificuldades financeiras conforme apontam Gazolla e Pelegrini (2011), adotam a comercialização dos produtos antes consumidos somente pela família, iniciando uma nova atividade que proporciona renda para suprir diversas necessidades. No entanto, as vias para a formalização poderiam ser diferentes, para que a mesma pudesse atender todos os agricultores, gerando melhorias de renda, qualificação dos alimentos, acesso a conhecimentos que auxiliassem o processo artesanal (sem perder a sua essência), inclusão social, resgate cultural, preocupações ecológicas, conscientização de consumidores e desenvolvimento regional.

\section{Considerações finais}

Compreender a importância da manutenção das famílias produtoras de alimentos com qualidade multidimensional leva ao caminho do aumento da diversidade alimentar. Utilizar esse potencial de forma a assegurar as famílias no meio rural, atrair turistas e proteger os consumidores dos grandes impérios alimentares deveria ser prioridade das ações governamentais. No entanto, o Estado continua negligenciando os pequenos produtores que usam das suas próprias estratégias para sobrevivência econômica, como é o caso da construção de mercados informais para agroindústrias de queijos artesanais. 
As agroindústrias familiares precisam ser vistas de acordo com a sua diversidade e heterogeneidade que representam em nossa cultura alimentar. A forma como é feita a fiscalização (higiênico-sanitária) dos alimentos exige dos agricultores um sistema perito formal, o que vai contra os principais e significados dos alimentos artesanais, com identidade própria, com características locais e que promovem inclusão social, resgate cultural, fortalecimento da agricultura familiar e desenvolvimento regional.

Os agricultores, através de sua ação, estão respondendo às dificuldades do ambiente institucional através da construção de mercados informais. Quando se analisa melhor as percepções dos agricultores, nota-se que eles não estão somente fragilizados pelas dificuldades burocráticas do sistema perito alimentar, mas estão mobilizados em prol de uma estratégia mais autônoma que busca incluir todas as realidades de produção artesanal, sem transformar a rica essência destes processos em técnicas que padronizam todos os alimentos.

As agroindústrias, mesmo sendo formais, criaram seus próprios mercados informais para escoar a produção, isso porque os mercados são criados essencialmente através das relações sociais e espaciais de proximidade entre os atores sociais (agricultores-consumidores) e não dependem das regras do sistema agroalimentar hegemônico, nem são resultado de uma economia imposta. As relações que os agricultores mantiveram com seus consumidores, por meio da comercialização em cadeias curtas, na maioria das vezes do tipo face a face, criaram laços de confiabilidade que proporcionam a reputação necessária para o funcionamento dos mercados.

O objetivo do artigo foi justamente o de evidenciar o porquê os mercados informais predominam, mesmo em condições sociais em que os empreendimentos econômicos (as agroindústrias) estão legalizados. A explicação a isso envolve um intrincado jogo de interesses, relações de poder e o ambiente institucional e regulamentar de alimentos, no qual se procurou evidenciar que os agricultores familiares traçam suas estratégias de produção e comercialização dos queijos artesanais de acordo com seus projetos de vida e de produção.

Os agricultores observam e refletem as escolhas dos consumidores ao fabricar e vender seus queijos artesanais (gostos e sabores requeridos pelos consumidores, não pasteurização do leite, preços dos queijos, construção de confiança, entre outros elementos), pois sabem que da boa aceitação destes dependem a construção dos seus mercados. Já no caso do Estado e das legislações agroalimentares, os agricultores tentam 'driblar' os regramentos institucionais estabelecidos, de forma a não seguir os parâmetros técnicos e produtivos da produção e distribuição dos queijos, mesmo sendo formalizados em nível municipal no SIM. Ou seja, há ainda um grande hiato entre o que o sistema perito alimentar requer dos agricultores e suas reais necessidades e anseios em torno da produção e construção social dos mercados artesanais de queijos. 


\section{REFERÊNCIAS}

ABRAMOVAY, R. Entre deus e o diabo: mercados e interação humana nas ciências sociais. Tempo Social. Vol. 16, n.2, p. 35-64, 2004.

AGNE, C. L. Mudanças institucionais na agricultura familiar: as políticas locais e as políticas públicas nas trajetórias das famílias nas Atividades de processamento de alimentos no Rio Grande do Sul. 2014. 260 f. Tese, Doutorado em Desenvolvimento Rural, Programa de Pós-Graduação em Desenvolvimento Rural da Faculdade de Ciências econômicas da UFRGS, Porto Alegre, 2014.

BAUMAN, Z. Vida para consumo: A transformação das pessoas em mercadoria. Editora Zahar. Rio de Janeiro, 2008.

COLETTI, V. D.; PERONDI, M. A. Produção de leite e resistência da agricultura familiar: comparando duas estratégias de comercialização local na região Sudoeste do Paraná - Brasil. Revista Redes (Santa Cruz do Sul. impresso), Vol. 20, p.236, 2015.

CRUZ, F. T. da.; MENASCHE, R. "Se o leite é cozido, o queijo não é Serrano": tradição, conhecimento e discurso instituído no controverso debate em torno de queijos feitos de leite cru. III Colóquio Agricultura Familiar e Desenvolvimento Rural. Porto Alegre- RS, 2011.

CHALITA, M. A. N. O consumo de queijo como referência para a análise do mercado de qualidade do produto. Revista de Economia e Sociologia Rural. Vol. 50, n 3, p.545-562, 2012.

SCHNEIDER, S.; FERRARI, D. L. Cadeias curtas, cooperação e produtos de qualidade na agricultura familiar: o processo de relocalização da produção agroalimentar em Santa Catarina. Organizações Rurais \& Agroindustriais. Vol. 17, n. 1, p. 56-71, 2016.

DORIGON, C. O Mercado Informal dos Produtores Coloniais da Região Oeste de Santa Catarina. V ENEC - Encontro Nacional de Estudos de Consumo. I Encontro Luso-Brasileiro de Estudos do Consumo. Tendências e ideologias do consumo no mundo contemporâneo. Rio de janeiro- RJ, 2010.

GAZOLLA, M.; PELEGRINI, G. Novos mercados da agricultura familiar: o caso das pequenas unidades agroindustriais produtoras de alimentos. IN: SCHNEIDER, S.; GAZOLLA, M. (ORGs.). Os atores do desenvolvimento rural: perspectivas teóricas e práticas sociais. Porto Alegre/RS. Editora UFRGS: 1ªdição, 2011, p. 133-150, 328.

GAZOLLA, M. Redefinindo as agroindústrias no Brasil: uma conceituação baseada em suas "condições alargadas" de reprodução social. VI Congresso Internacional Sistemas Agroalimentares Localizados. Florianópolis- SC, 2013. 
GAZOLLA, M. Políticas e programas públicos para as agroindústrias familiares: uma análise do PRONAF E PAF/RS. $52^{\circ}$ Congresso da Sociedade Brasileira de Economia, Administração e Sociologia Rural. Goiânia-GO, 2014.

GAZOLLA, M. Segurança alimentar e nutricional e agroindústrias familiares: políticas públicas e ações locais. Segurança Alimentar e Nutricional. Campinas, SP, Vol. 21, n. 2, abr., p. 527-540, 2014.

GAZOLLA, M.; SCHNEIDER, S. Cadeias curtas e redes agroalimentares alternativas: negócios e mercados da agricultura familiar. Editora da UFRGS: Porto Alegre/RS. 523p. (Série Estudos Rurais), 2017.

GIDDENS, A.; ULRICH, B.; SCOTT, L. Modernização reflexiva: política, tradição e estética na ordem social moderna. Tradução de Magda Lopes. São Paulo: UNESP. 1997.

GROSSI, M., E, Del.; SILVA, J. G, da. Fábrica do Agricultor: Agregando valor e gerando ocupações não agrícolas. SOBER. 2002.

IBGE. Censo Agropecuário 2006. Sistema Automático de Recuperação de Dados (SIDRA). Atualização de dados de 2012. < Disponível em:

http://www.cidades.ibge.gov.br/xtras/temas.php?lang=\&codmun=411120\&idtema=3 \&search=parana|itapejara-d`oeste|censo-agropecuario-2006. Acesso em 27/04/2015.>

LANG, T; HEASMAN, M. Food Wars: the battle for minds, mouths and markets. London: Earthscan, 2004.

LONG, N. Sociologia del desarollo: una perspectiva centrada en el actor. Colección Investigaciones. México: Centro de Investigaciones y Estudios Superiores en Antropologia Social, 2006.

MALUF, R. S. Mercados agroalimentares e agricultura familiar no Brasil: agregação de valor, cadeias integradas e circuitos regionais. Ensaios. FEE, v. 25, n. 1 p. 299-322, 2004.

MARSDEN, T.; BANKS, J.; BRISTOW, G. Food supply chain approaches: exploring their role in rural development. Sociologia Ruralis, Vol.40, n.4, p.424-438, 2000.

MATTEDI, C. R. A Construção Social do Mercado em Durkheim e Weber: Análise do papel das instituições na sociologia econômica clássica. Revista Brasileira de Ciências Sociais. Vol. $20 \mathrm{n}^{\circ}$ 57, 2005.

MIOR, L. C. Agricultura familiar, agroindústria e desenvolvimento territorial. Colóquio Internacional de Desenvolvimento rural sustentável. Florianópolis- SC. 2007. 
MIOR, L. C. Trajetórias das Agroindústrias Familiares Rurais no Estado de Santa Catarina (Brasil). IV Congresso Internacional de la Red SIAL. Mar del PlataArgentina. 2008.

NIERDELE, P. A.; WESZ, V. J. J. A Agroindústria Familiar na região de Missões: construção de autonomia $r$ diversificação dos meios de vida. Revista REDES. Santa Cruz do Sul. N. 3, p. 75-102, 2009.

NIEDERLE, P. A. Indicações geográficas e processos de qualificação nos mercados agroalimentares. In: NIEDERLE, P. A. (Org.) Indicações geográficas: qualidade e origem nos mercados alimentares. Porto Alegre: UFRGS. 2013, 296p, 23-54pp. (Série Estudos Rurais).

PORTILHO, F. Novos atores no mercado: movimentos sociais econômicos e consumidores politizados. Revista Política \& Sociedade. Vol. 8, n. 15, p. 199-224, 2009.

PLOEG, van der Jan Dowve. Camponeses e Impérios alimentare: lutas por autonomia e sustentabilidade na era da globalização. Porto Alegre: UFRGS, 2008.

PREZOTTO, L. L. Uma concepção de agroindústria rural de pequeno porte. Revista de Ciências Humanas. n. 31, p.133-154, 2002.

RENTING, H., MARSDEN, T.K. and BANKS, J. Understanding alternative food networks: exploring the role of short food supply chains in rural development. Environment and Planning. Vol. 35, 393-411, 2003.

SILVEIRA, P. R. C. da. \& ZIMERMANN, S. A Qualidade em Circuitos Regionais de produção de Alimentos numa Perspectiva de Segurança Alimentar. IN: FROELICH, M. \& DIESEL, V. (ORGs.). Espaço Rural e Desenvolvimento Regional. Editora: UNIJUÍ, 2004.

SILVEIRA, P. R. C. da; HEINZ, C. Controle de Qualidade normativo e qualidade ampla: princípios para re-estruturação e qualificação da produção artesanal de alimentos. Seminário sobre Agroindústria Familiar e Desenvolvimento Rural. São Luis Gonzaga-RS, 2005. Anais, São Luis Gonzaga: UERGS, 2005. CD-ROOM.

SILVEIRA, P. R.C.; GUIMARÃES, G. M. Por trás da falsa homogeneidade do termo agroindústria familiar rural: indefinição conceitual e incoerência das políticas públicas. Congresso da Sociedade Brasileira de Sistemas de Produção, Fortaleza, CE. 2007.

SCHNEIDER, S. Mercados e agricultura familiar. In: MARQUES, F. C.; CONTERATO, M. A.; SCHNEIDER, S. (ORGs.). Construção de mercados e agricultura familiar: desafios para o desenvolvimento rural. Porto Alegre: Editora da UFRGS. 2016, 416p. (Série Estudos Rurais). 
WAQUIL, P. D. ; SANTOS, S. J.; FISCHER, A.; SEHNEM, S.; GIANEZINI, M.

Padronização de Produtos das Agroindústrias Rurais e a Inserção nos Mercados.

Redes. Santa Cruz do Sul. n. 2, p. 155-176, 2013.

WILKINSON, J. Sociologia econômica e o funcionamento dos mercados: inputs para analisar os micro e pequenos empreendimentos agroindustriais no Brasil. Ensaios. FEE, N. 2, p. 805-825, 2002.

WILKINSON, J. Mercados, redes e valores: o novo mundo da agricultura familiar. Porto Alegre: Editora da UFRGS, (Série Estudos Rurais). 213p., 2008.

Miguel Angelo Perondi. Professor do Programa de Pós Graduação em Desenvolvimento Regional (PPGDR) da UTFPR-Campus Pato Branco. Rodovia do Conhecimento - Km 1, Bom Retiro, CEP: 85503390 - Pato Branco, PR - Brasil miguelangeloperondi@gmail.com

Mariana Beal Dengo. Engenheira Agrônoma, mestranda em Desenvolvimento Regional pelo Programa de Pós Graduação em Desenvolvimento Regional, PPGDR-Campus Pato Branco. maribd.vre@gmail.com

Marcio Gazolla. Professor do Programa de Pós Graduação em Desenvolvimento Regional (PPGDR) da UTFPR-Campus Pato Branco. marciogazolla@gmail.com

\section{Submetido em: 30/03/2018}

\section{Aprovado em: 21/12/2018}

Como citar: PERONDI, Miguel Angelo; BEAL DENGO, Mariana; GAZOLLA, Marcio. Mercados das agroindústrias familiares de queijo artesanal do Sudoeste do Paraná. Redes, Santa Cruz do Sul, v. 24, n. 1, p. 246-269, jan. 2019. ISSN 1982-6745. Disponível em: https://doi.org/10.17058/redes.v24i1.11895. 